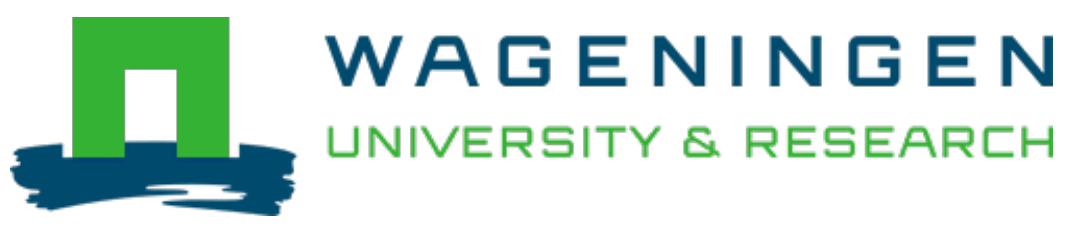

\author{
Nudging healthy eating in Dutch sports canteens : A multi-method case study \\ Public Health Nutrition \\ Rookhuijzen, Merije; Vet, Emely \\ https://doi.org/10.1017/S1368980020002013
}

This article is made publicly available in the institutional repository of Wageningen University and Research, under the terms of article $25 \mathrm{fa}$ of the Dutch Copyright Act, also known as the Amendment Taverne. This has been done with explicit consent by the author.

Article $25 \mathrm{fa}$ states that the author of a short scientific work funded either wholly or partially by Dutch public funds is entitled to make that work publicly available for no consideration following a reasonable period of time after the work was first published, provided that clear reference is made to the source of the first publication of the work.

This publication is distributed under The Association of Universities in the Netherlands (VSNU) 'Article $25 \mathrm{fa}$

implementation' project. In this project research outputs of researchers employed by Dutch Universities that comply with the legal requirements of Article $25 \mathrm{fa}$ of the Dutch Copyright Act are distributed online and free of cost or other barriers in institutional repositories. Research outputs are distributed six months after their first online publication in the original published version and with proper attribution to the source of the original publication.

You are permitted to download and use the publication for personal purposes. All rights remain with the author(s) and / or copyright owner(s) of this work. Any use of the publication or parts of it other than authorised under article $25 \mathrm{fa}$ of the Dutch Copyright act is prohibited. Wageningen University \& Research and the author(s) of this publication shall not be held responsible or liable for any damages resulting from your (re)use of this publication.

For questions regarding the public availability of this article please contact openscience.library@wur.nl 


\title{
Nudging healthy eating in Dutch sports canteens: a multi-method case study
}

\author{
Merije van Rookhuijzen* (1) and Emely de Vet \\ Wageningen University and Research, Wageningen 6706 KN, The Netherlands
}

Submitted 10 September 2019: Final revision received 25 March 2020: Accepted 27 May 2020

\begin{abstract}
Objective: To provide a micro-investigation into the long-term effects and process of implementation of a nudge intervention on food choice in sports canteens. Design: Multi-method case study.

Setting: Eight products were added to the range of foods and drinks in two football canteens in the Netherlands for 3 and 15 weeks, serving as a baseline period. In the intervention period, these products were promoted with the use of salience, scarcity, availability and default nudges, for 26 and 16 weeks, respectively. Aside from the collection of sales and revenue data, reach, acceptability, adherence and applicability were measured using observations, questionnaires and interviews.

Participants: Questionnaires were filled in by seventy and fifty-nine visitors of the canteens. Four interviews were held with board members and canteen personnel. Results: Mixed results were obtained regarding the suitability of nudges to be used to promote healthy eating in sports clubs. Sales and revenue data did show positive trends, the intervention was seen as acceptable by all stakeholders and the intervention had a large reach. However, adherence to the intervention in both canteens and the effects of the nudges on the total consumption pattern were low. Factors were identified that promoted or hindered the intervention at an individual, interventional and organisational level.

Conclusions: Nudges seem to be a valuable addition to other efforts to combat unhealthy eating. However, the extent of their impact as a single intervention tool is limited in the current food-abundant environment.
\end{abstract}

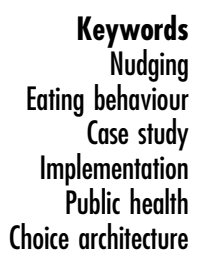

Following the increasing awareness that dietary habits are strongly linked to many health outcomes, much has been invested in the development of interventions aimed at improving our diets. Initially, interventions mainly focussed on encouraging people to reflect on their eating behaviour. And, although interventions promoting health behaviours have been found able to induce changes in intention, this has not been accompanied by equally large changes in behaviour. To illustrate, a meta-analysis of Webb \& Sheeran ${ }^{(1)}$ found that a medium-to-large change in intention ( $d=0.66)$ was followed by a small-to-medium change in actual behaviour $(d=0.36)$ according to categorisations by Cohen ${ }^{(2)}$.

One of the reasons put forward for the observation that people are unable to translate dietary knowledge into practice, even with good intentions, is that eating behaviour is largely under the control of automatic (rather than reflective) processes ${ }^{(3-6)}$. This ensures fast and rather effortless decision-making for the large number of daily food choices we make. However, due to its reliance upon heuristics (rules of thumb), the system is prone to $\operatorname{error}^{(7)}$, which may lead to decisions opposite to those of our intentions.

\section{'If you cannot beat them join them'}

Considering the above, the answer to the question how healthy diets may best be promoted may seem obvious: by using the automatic nature of our dietary decisions to our advantage. Nudging is a strategy that exploits the manner in which automatic processes guide our behaviour to predictably affect it by changing the architecture in which we make decisions, without limiting the set of options ${ }^{(8,9)}$. For example, placing unhealthy items out of direct reach reduces the number of participants consuming those items with $53 \%{ }^{(10)}$. Many scholars, therefore, consider nudges a potentially valuable addition or even alternative to current interventions ${ }^{(11)}$, which is reflected in the plethora of metaanalyses and systematic reviews on the effect of nudging on eating behaviour ${ }^{(12-15)}$. 
Most of these studies conclude that nudges are able to influence eating behaviour, although, according to the classification made by Cohen ${ }^{(2)}$, effect sizes tend to range from small to medium. For example, in their meta-analysis of nudges used in ninety-six field experiments, Cadario \& Chandon $^{(16)}$ report an average small effect size of $d=0.23$ (translating into a $518.816 \mathrm{~kJ}$ change in energy intake). These findings tend to be stable across highly controlled laboratory studies and large field studies with multiple sites, which suggest a promising future for nudges to be included in interventions aimed at promoting healthy eating in various contexts.

\section{From theory to practice}

Although there seems to be enough evidence indicating the usefulness of nudging as a strategy to influence dietary behaviour, aspects that cause success in efficacy research are markedly different than those in effectiveness research $^{(17)}$. In other words, behaviour change under highly controlled circumstances does not equal substantial behaviour change under real-world circumstances. This means that although nudges may often be thought of as effective, and easy and cheap to implement and maintain, one could argue that their subtlety makes their effectiveness especially vulnerable to even the slightest of changes. For example, nudging products by changing their placement only needs a single-hand movement to be undone. A detailed look into the process of implementation and its effects on the ability of nudges to change behaviour will provide information about the barriers and challenges of the use of nudges in applied settings. Only then can the effects of nudge interventions be optimised.

\section{Current study}

In the current study, we aimed to assess the feasibility of using a nudge intervention in a real-life setting by studying outcome and process with a multi-method in-depth analysis over a longer period. More specifically, the process was studied by addressing the reach (the number of people potentially exposed to the intervention), acceptability (the extent to which the intervention is deemed acceptable by stakeholders), adherence (the extent to which the intervention was carried out as planned) and applicability (whether the population, intervention and context are suitable for the intervention) of the intervention.

We chose two football canteens to serve as cases. One reason for this choice was the often unhealthy nature of the canteens, selling only few healthy products (in 2011, $72 \%$ of the assortment in sport canteens was deemed unhealthy $\left.{ }^{(18)}\right)$. Football (soccer) is one of the biggest sports of the Netherlands with approximately 3000 clubs with 1.2 million members of all ages and backgrounds. The canteens that are part of most clubs provide an important source of income. Football clubs, therefore, provide an important setting for the promotion of healthy eating, potentially reaching many people. Moreover, sport facilities can be considered a more manageable and easier to regulate context than locations such as grocery stores for the implementation of nudges, since the choice architect himself/herself is often present on the floor.

\section{Methods}

\section{Canteens}

Purposive sampling was used to recruit two canteens, denoted as canteens A and B, from moderately sized football clubs (with 800 and 1000 members, respectively) in the middle of the Netherlands. The clubs were required to play in different leagues to avoid that teams would visit each other's canteen. The opening hours of the canteens depended on the schedules of the trainings and matches, but, in general, they were open during weekends and some evenings during the week. During opening hours, all visitors were able to purchase products by asking for the desired product at the counter. Similar products were sold in both canteens, among which were deep fried and cold snacks, a variety of soft and alcoholic drinks, sandwiches and candy. Products were sold by both regular and episodic volunteers (mostly family members of football players).

\section{Participants}

Questionnaires were distributed to visitors in both canteens at two occasions during the study. The first questionnaire assessed reach and (parts of) applicability and was presented on a random day during the intervention phase. It was (partially) completed by seventy visitors from both canteens $\left(70 \%\right.$ male, $M_{\text {age }}=36.91$ years, $\left.\mathrm{SD}=20 \cdot 14\right)$. The second questionnaire assessed acceptability and (parts of) applicability and was presented during the last day of the study. It was (partially) completed by fifty-nine visitors from both canteens $\left(74 \%\right.$ male, $M_{\text {age }}=22.64$ years, $\mathrm{SD}=18 \cdot 77$ ). All visitors to both canteens, among which were players and spectators, could fill in the questionnaires. They had to actively take the questionnaires that were placed on tables and the counter by the first researcher. At the top of the questionnaires, participants were informed that by filling in the questionnaire, they consented to the use of the anonymous data for scientific purposes. Four semi-structured interviews were held by the first researcher at the end of the study with one board member and one member of the canteen personnel of each canteen (three males and one female) to inquire about their perceived adherence, acceptability and applicability. Both the board members and canteen personnel were chosen because they had the biggest influence on the assortment and placing of food products in the canteen. Written informed consent of the interviewees was obtained for each audio-taped interview. 


\section{Observations}

Observations regarding the reach of the intervention were made on a random day during the intervention phase. Both canteens were each visited eight times on random moments to measure adherence.

\section{Design and procedure}

The design of the study can be found in Fig. 1. A multiple case study was conducted, in which a nudge intervention was implemented to promote healthy eating in two football canteens. The study consisted of two phases. In the baseline phase, the assortment of the canteens was expanded with eight healthier products that were unobtrusively placed in the canteens (e.g., at the lowest shelf of the refrigerator). Prices for these products were determined by canteen personnel to match the price levels of other products sold in the canteen. In the nudge intervention phase, selection of these novel products was stimulated through the use of various nudges.

The study lasted an entire football season. The baseline phase lasted 3 weeks in canteen A and 15 weeks in canteen B. This phase was followed by a 26-week and 16-week nudge intervention in canteens $\mathrm{A}$ and $\mathrm{B}$, respectively. The difference in length of the baseline and intervention period between both canteens was chosen because this enabled a long-term effect measurement in canteen A, while it enabled a longer baseline period in canteen $\mathrm{B}$. During observations, intervention deviations from protocol were corrected by the first researcher in canteen A, but not in canteen B. This approach enabled a more controlled examination of the sales records of canteen A when the nudge intervention was implemented as intended and a more process-oriented examination of the intervention in canteen B under real-life circumstances.

\section{Intervention}

\section{Food and drinks}

The added products included bananas (as alternative for highly processed snacks), flavoured water (as alternative to sugared drinks), a zero-sugar sports drink (as alternative to regular sugary sports drinks), a yogurt snack without added sugar and extra protein (as alternative to sugary yogurt snacks), a cereal bar low in energy content (as alternative to chocolate bars), popcorn (as alternative to crisps), a grilled sandwich made from bread high in fibre (as alternative to regular grilled sandwiches made with white bread) and a snack made of baked peas and maize (as alternative to cocktail nuts). If sponsoring contracts did not allow for certain brands to be sold in the canteen, an equivalent of another brand was chosen. The products were selected by a sports dietician to be optimally suited for consumption before and after training or as healthier alternatives to existing snacks. The products contained less sugar, saturated fat and energy content and more protein and fibre relative to available alternative products in the same food category. All products were not yet available in both canteens before the study, except for the bananas, which were already sold in canteen B.

\section{Nudges}

Suitable nudges to promote the added products were selected based on (i) an examination of systematic reviews, meta-analyses and individual studies on the effect of heuristics and nudges on eating behaviour ${ }^{(12,13,19-30)}$ and (ii) contextual considerations about the feasibility of using certain types of nudges in the football canteens. This resulted in the use of salience, scarcity, availability and default nudges. Definitions of these nudges and their use during the intervention phase can be found in Table 1 .

\section{Measures}

Sales figures and revenue data of every product in the canteen were based on point-of-sale data. In canteen A, sales figures were available per week. In canteen B, sales figures were aggregated to indicate sales data per phase because sales of some products needed to be recorded by personnel or volunteers themselves, which turned out not to be feasible on a weekly basis. For comparison reasons, revenue data of the same period as the intervention phase in the preceding year of both canteens were obtained.

Reach was measured by counting the number of people visiting the canteen on a single day, collecting sales figures and data on the amount of transactions made that day and through questionnaires that were filled in on the same

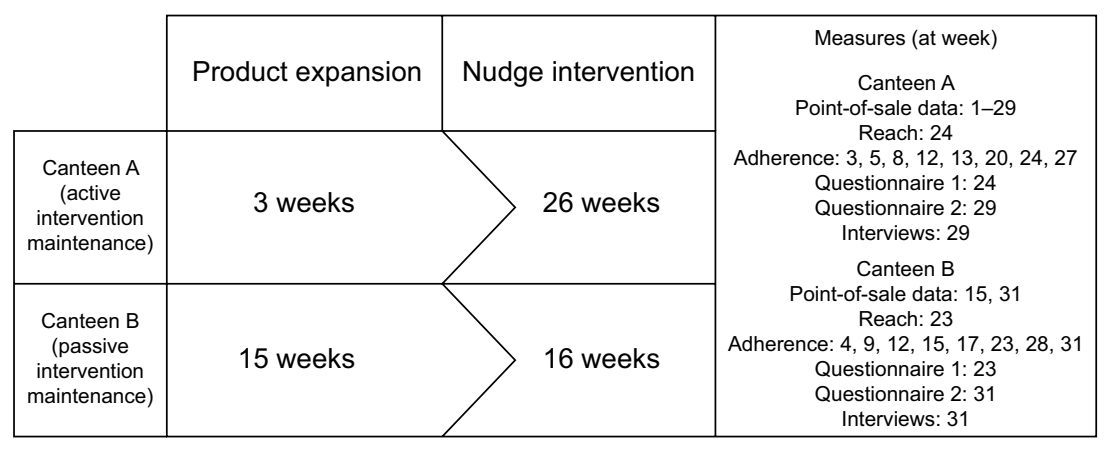

Fig. 1 Design of the study and moments of measurement 
Table 1 Nudges, definitions and their use during the intervention

\begin{tabular}{|c|c|c|}
\hline Nudge & Definition & Use during intervention \\
\hline Salience & $\begin{array}{l}\text { Products that are prominently placed tend to } \\
\text { draw our attention more than products that } \\
\text { are less visible }\end{array}$ & $\begin{array}{l}\text { Many of the products used in the current study were placed } \\
\text { at eye level (flavoured water, zero-sugar sports drink, } \\
\text { yogurt snack in canteens } A \text { and } B \text {, popcorn in canteen } A \text {, } \\
\text { baked peas and maize snack in canteen } A)^{\star} \text {, placed more } \\
\text { in sight or reach (bananas in canteen } A \text {, cereal bar, } \\
\text { popcorn in canteen B) or the ratio of the product with } \\
\text { similar products was increased (bananas in canteen B). } \\
\text { Moreover, the zero-sugar sports drink was placed in the } \\
\text { refrigerator in more than one row in both canteens, which } \\
\text { was also the case for the yogurt snack in canteen } A\end{array}$ \\
\hline Scarcity & $\begin{array}{l}\text { Products whose availability is limited are valued } \\
\text { more than products whose availability is } \\
\text { in abundance }\end{array}$ & $\begin{array}{l}\text { A picture of the grilled sandwich that was placed on the } \\
\text { counter contained the message that it was available } \\
\text { while supplies last }\end{array}$ \\
\hline Availability & $\begin{array}{l}\text { The tendency to rely on immediate examples } \\
\text { that come to mind when making a decision } \\
\text { is called the availability heuristic }\end{array}$ & A picture of the grilled sandwich was placed on the counter \\
\hline Default & $\begin{array}{l}\text { The default option is the option that will be obtained } \\
\text { when one does not actively intervene. Since } \\
\text { intervening requires effort, we will often choose } \\
\text { the option that is the default }\end{array}$ & $\begin{array}{l}\text { Personnel of canteen A was required to present visitors } \\
\text { asking for the sports drink with the zero-sugar version. } \\
\text { They were only allowed to be presented with the regular } \\
\text { version when asked specifically. Canteen B was not willing } \\
\text { to implement the default nudge. Therefore, this nudge was } \\
\text { changed into a prompted choice nudge: When visitors } \\
\text { asked for a sports drink, personnel had to ask whether } \\
\text { the person wanted the regular or zero-sugar version }\end{array}$ \\
\hline
\end{tabular}

${ }^{*}$ No nudges were planned for the baked peas and maize snack in canteen B, since it was already planned to take the product out of product range before the nudge plan was drafted.

day. Visitors of the canteen were counted using a mechanical tally counter. Two people, among which the first researcher, would unobtrusively sit at the back of the canteen, counting the number of visitors entering the canteen during the entire day. If one of the observers noticed that a visitor had already entered before during that day, the individual was not counted a second time. In the questionnaires, aside from gender and age, visitors were asked how often they visited the canteen, how often they had bought products during the last month and whether and what they had bought that day.

Acceptability was measured through questionnaires targeted at visitors and through semi-structured interviews with board members and canteen personnel. In the questionnaires, visitors were first asked age and gender and given a general explanation of nudges. Subsequently, they were asked to rate on five-point Likert scales ranging from 1 (totally unacceptable/undesirable/unagreeable/wrong) to 5 (totally acceptable/desirable/agreeable/right) how acceptable, desirable, agreeable and right they thought it was to (i) use nudges by the football canteen to let people make healthier choices (Cronbach's $\alpha=0.93$ ), (ii) use nudges to influence their behaviour (Cronbach's $\alpha=0.92$ ) and (iii) use nudges to influence others'behaviour (Cronbach's $\alpha=0 \cdot 97$ ). Moreover, they were asked whether they thought that nudges stimulating healthy eating were in place in the football canteen on a five-point Likert scale ranging from 1 (totally disagree) to 5 (totally agree). Interviewees were asked: How acceptable is the use of nudges to promote healthy eating in the canteen to you? Why?

Adherence was measured by observations made by the researcher during visits of the canteens. Availability, placement and prices of the products were reported during every visit (eight times per canteen in total). Hawe et al. ${ }^{(31)}$ argue that adherence assessment should be based on the extent to which the function of different components of the intervention was delivered according to plan. Therefore, minor changes in placement that did not affect the function of the nudge were not regarded as deviations (e.g., drinks could be placed either to the right or the left of the refrigerator, but always at eye level). During the visits and interviews, respondents were asked about deviations from the protocol in terms of availability, placement and pricing: Why was the specific product not available, or why was it placed or priced differently?

An applicability analysis is essential in assessing whether the intervention can be implemented in similar settings (or whether and which changes have to made before the intervention can be implemented in similar settings). For this purpose, the wide range of questions asked through questionnaires and interviews was divided into determinants at the individual, interventional and organisational level.

Individual level: Healthy eating goals of visitors were assessed with the items 'I try my best to eat healthily' and 'Eating healthily is important to me' which had to be 
rated on a five-point Likert scale ranging from 1 (totally disagree) to 5 (totally agree) (Cronbach's $\alpha=0 \cdot 85$ ). They were also asked about unhealthy eating being part of the football culture with the items 'Unhealthy eating in the football canteen is just part of playing football' and 'It is normal to eat unhealthy in the football canteen' which had to be rated on a five-point Likert scale ranging from 1 (totally disagree) to 5 (totally agree) (Cronbach's $\alpha=0 \cdot 61$ ). Moreover, visitors were asked about the degree of habitualness of buying things in the canteen by agreeing or disagreeing with the items 'I often buy the same things in the football canteen' and 'I tend to buy things in the football canteen without thinking' on a five-point Likert scale ranging from 1 (totally disagree) to 5 (totally agree) (Cronbach's $\alpha=-0.74$; items discussed separately). Interviewees were asked about the characteristics of visitors of the canteen that could help or hinder implementation and effectiveness of the intervention.

Interventional level: During semi-structured interviews, board members and canteen personnel were asked about the use of nudges as a tool for improving healthy eating in football canteens, about the perceived effects of the intervention (whether they thought the intervention was able to reach its goals), about characteristics of the intervention that could help or hinder implementation and effectiveness of the intervention, suggestions for improvement of the interventions and about elements of the intervention they intended to maintain.

Organisational level: In questionnaires, visitors were asked to indicate on a five-point Likert scale ranging from 1 (totally disagree) to 5 (totally agree) whether they agreed with the items: 'I find it important that the football canteen stimulates healthy eating' and 'The supply of healthy products in the football canteen is sufficient'. Interviewees were asked: What is the role of football canteens in the promotion of healthy eating? and How important is revenue for decisions made for the promotion of healthy eating?

\section{Data analyses}

Quantitative data from observations and questionnaires were analysed by calculating descriptive statistics. Since the number of participants who filled in the questionnaires was low, data from both canteens were averaged, unless answers between the canteens differed significantly. Scores on items from constructs that were measured with more than one item with Cronbach's $\alpha>0.6$ were also averaged. When frequencies are reported, a differentiation is made between respondents rating constructs or items below (disagree), on (neutral) or above (agree) the centre of the measuring scale. Interview recordings were transcribed, coded with themes and compared across interviewees. When content between interviewees differed, this is discussed separately. Themes were partly driven by the different constructs that were measured but mostly emerged during coding.

\section{Results}

\section{Sales and revenue}

Sales of the nudged products showed a mean increase of $87.20 \%$ (5.52 products) in canteen A and $138.90 \%$ (16.39 products) in canteen $\mathrm{B}$ per week during the intervention period relative to the baseline period. When the percentage of the total sales that is made up of nudged products is examined, there was an increase of $135.14 \%$ in canteen $\mathrm{A}$ and an increase of $148.08 \%$ in canteen B during the intervention period relative to the baseline period. However, although the added products made up of a substantial percentage of the total product range in both canteens (7.56\% in canteen A and $4.52 \%$ in canteen B), only a small percentage of the total sales consisted of these products in the nudge intervention phase $(0.87 \%$ in canteen $\mathrm{A}$ and $1.29 \%$ in canteen B). Moreover, nearly all of the best-selling product categories consisted of unhealthy products, high in sugar, saturated fat and energy content. Descriptive statistics for canteens A and B for different product categories can be found in the online supplementary material, Supplemental Files 1 and 2, respectively. Figure 2 shows the percentage of the total sales made up of nudged products per week at canteen A. It can be observed here that sales do seem to have increased right after nudge implementation, then decreased and again gradually increased during the remainder of the intervention. The total revenue of both canteens slightly increased during the nudge intervention phase when compared with the same period the year before (an increase of $1.18 \%$ in canteen $\mathrm{A}$ and $1.94 \%$ in canteen B).

\section{Reach}

On the day of measurement, canteens A and B were visited by approximately 1081 and 1705 people, respectively. In

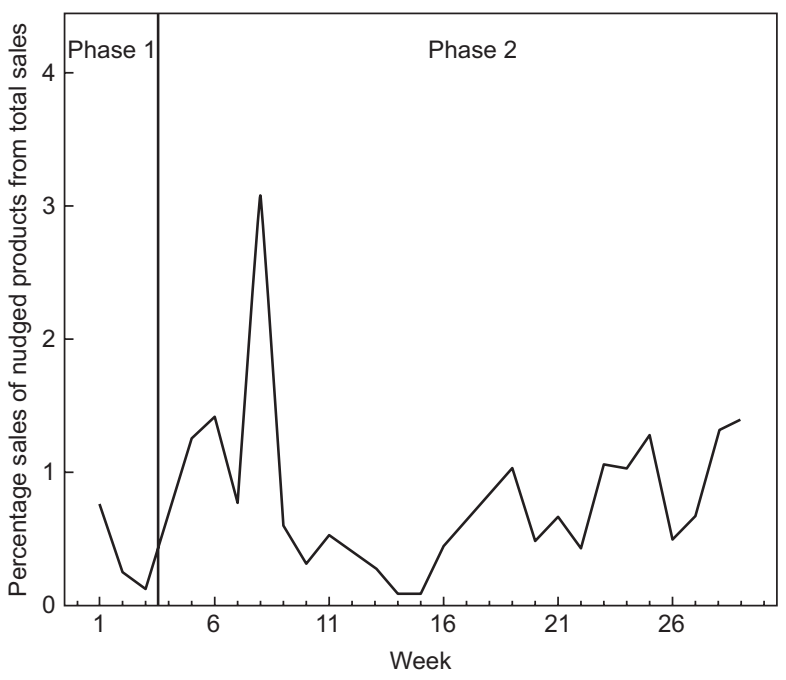

Fig. 2 Sales of nudged products at canteen A as percentage of total food sales per week in the baseline and the intervention phase 
canteen A, 1020 products were sold during 468 transactions. In canteen B, 2931 products were sold during 1062 transactions. In the questionnaires, $64 \%$ of participants reported to visit the canteen at least once per week, and the average number of reported purchases during the last month was 5.61 (SD 5.04). ${ }^{1}$ Eighty percent of respondents had bought a product on the day the questionnaire was conducted. Consumed products could for the largest part be categorised into hot drinks (32\%), sandwiches/bread/ wraps (22\%) and fried foods/foods from the grill (14\%).

\section{Acceptability}

Descriptive statistics of the acceptability items can be found in Table 2. In both canteens, most visitors agreed with the statement that the football canteen uses nudging to influence eating behaviour while also finding it an acceptable means to use to influence eating behaviour in the canteen in general and to influence oneself and others. From the interviews it became apparent that the board members and canteen personnel also thought of nudges as acceptable to be used to promote healthy eating in both football canteens:

Well, in the end, it's the consumer who is standing there and decides what he orders and consumes. Well yeab, and if we could trigger consumers a bit more by placing items at eye level or by placing them on the cash desk., well, that's fine. - Board member, male, canteen $\mathrm{B}$

Table 2 Descriptive statistics of acceptability items

\begin{tabular}{lccccc}
\hline & $M$ & $95 \% \mathrm{Cl}$ & $\begin{array}{c}\text { Disagree } \\
(\%)\end{array}$ & $\begin{array}{c}\text { Neutral } \\
(\%)\end{array}$ & $\begin{array}{c}\text { Agree } \\
(\%)\end{array}$ \\
\hline $\begin{array}{l}\text { Football canteen } \\
\text { uses nudges }\end{array}$ & 3.56 & $3.22,3.90$ & 20.00 & 24.00 & 56.00 \\
$\begin{array}{l}\text { Nudges } \\
\text { acceptable } \\
\text { means to use } \\
\text { in canteen }\end{array}$ & 4.14 & $3.88,4.41$ & 10.00 & 12.00 & 78.00 \\
$\begin{array}{l}\text { Nudges } \\
\text { acceptable to } \\
\text { influence } \\
\text { oneself }\end{array}$ & 3.84 & $3.57,4.11$ & 8.00 & 26.00 & 66.00 \\
$\begin{array}{c}\text { Nudges } \\
\text { acceptable to } \\
\text { influence others }\end{array}$ & 3.89 & $3.60,4.18$ & 14.29 & 18.37 & 67.35 \\
\hline
\end{tabular}

\section{Adberence}

(Non-)adherence to broadening the assortment

During the baseline phase, the added products were available in canteen A during $87.50 \%$ and in canteen B during $75.00 \%$ of the observations. Of these times, the products were placed according to plan (no nudges) during 71.43 and $87.50 \%$ of the observations in canteens $\mathrm{A}$ and $\mathrm{B}$,

${ }^{1}$ One outlier was removed from analysis of the item assessing the frequency of bought products in the last month, since it was deemed an extreme estimate. respectively. Prices were as agreed during $100 \%$ of the observations in both canteens.

Two of the added products were removed from the assortment (the yogurt and savoury snack) by personnel of both canteens, because of their low shelf life, expensiveness and low sales. Moreover, the savoury snack had, according to the interviewees, a disappointing taste:

People nearly broke their teeth on it and it doesn't taste like anything. - Personnel member, female, canteen B

Another reason for the unavailability of some products is that wholesalers sometimes could not deliver a product. Moreover, bananas were not always available, since they are often purchased only once per week, and therefore already sold out later that week or no longer acceptable to sell.

\section{(Non-)adherence to the nudge intervention}

During the nudge intervention phase, the added products were available during 66.67 and $71.88 \%$ of the observations in canteens $\mathrm{A}$ and $\mathrm{B}$, respectively. Of these times, the products were placed according to plan (with nudges) during 68.75 and $52.17 \%$ of the observations in canteens A and B, respectively. Prices were as agreed during $100 \%$ of the observations in canteen A and during $95.65 \%$ of the observations in canteen B. ${ }^{2,3,4}$ The high number of frequently changing volunteers working in the canteen was put forward as a reason for non-adherence:

Well, actually, you have to instruct new volunteers every week. And if you once forget it, they will not know and take initiative and well, that's not what you want. - Board member, male, canteen A

Lowest adherence was observed for the default/prompted choice nudge. Personnel deemed it too time consuming at busy times. Moreover, after some time, visitors became familiar with the nudge, leading to personnel not willing to enforce the nudge. In addition, canteen B personnel failed to implement the salience nudge of the bananas:

You've only got 15 to 20 minutes during half-time. And when there are 100 people in front of you, you're not going ask such questions. - Personnel member, male, canteen A

\footnotetext{
${ }^{2}$ As was the case in canteen B, canteen A changed the default nudge of the sports drink with zero added sugar into a prompted choice, since canteen personnel noticed that visitors sometimes already opened the zero-sugar drink before realising that it was not their preferred choice.

${ }^{3} \mathrm{Also}$, at one instance of measuring adherence in canteen $\mathrm{A}$, the canteen was closed due to bad weather. Therefore, adherence measurements are based on seven observations instead of eight.

${ }^{4}$ Moreover, the vending machine of canteen $\mathrm{B}$ broke down during the study. Therefore, other arrangements were made with the personnel for the placement of the products. However, the same type of nudges were used.
} 


\section{Applicability}

Determinants of the applicability of the intervention are discussed at the individual, interventional and organisational level. These determinants and their interplay can be found in Fig. 3.

\section{User level}

Descriptive statistics of the factors that could influence the effects of the intervention can be found in Table 3. Most visitors agreed with having the goal to eat healthily, but many still considered unhealthy eating a part of the football culture. A clear pattern regarding the habitual nature of purchasing products in the football canteen could not be observed.

The interviewees all mentioned unhealthy eating being part of the football culture, which could hinder the adoption of healthy eating practices:

The football club has got a specific culture (...) which translates into a meatball during half-time.

- Personnel member, male, canteen A
Most also mentioned the habitual nature of eating behaviour of adults, which also acts as a barrier to change. However, they did not specifically mention this habitual nature in relation to the context of football canteens, but in contrast to the eating behaviours of children which were considered less routinised and thus more receptive to change attempts. Therefore, some suggested that healthy eating promotion activities should especially focus on children, because the eating behaviour of adults was deemed resistant to change using small alterations such as nudges. Adults often have predefined what they want to consume:

Well yeah, I do think that you have to start with children with that. Then it becomes a natural thing ... then there's no need to switch. For us, it's more difficult. - Personnel member, female, canteen B

Personnel of canteen A noticed that especially children were consumers of the nudged products. Personnel of canteen $\mathrm{B}$ thought that especially healthy people consumed the nudged products.
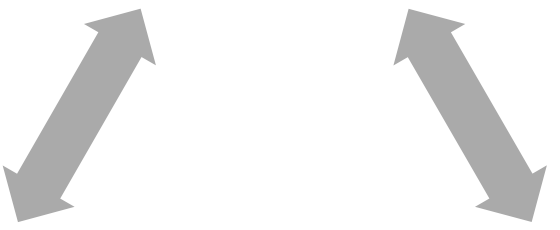

Interventional
$\begin{gathered}\text { Characteristics of the products (e.g., } \\ \text { shelf-life, familiarity, flavour, quantity } \\ \text { for money) } \\ \text { Characteristics of the nudges: fit with } \\ \text { organisational practices (e.g., effort) }\end{gathered}$

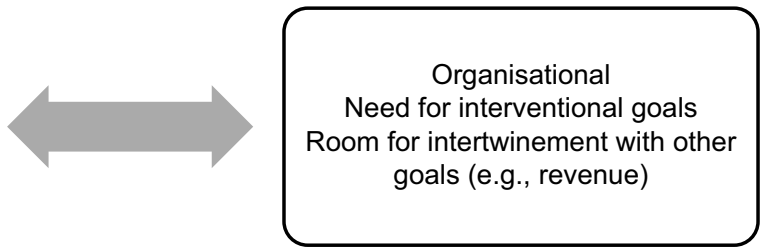

Fig. 3 Interplay between factors determining applicability of the food-related nudge intervention in sports canteens

Table 3 Descriptive statistics of factors at the user and organisational level

\begin{tabular}{|c|c|c|c|c|c|}
\hline & $M$ & $95 \% \mathrm{Cl}$ & Disagree $(\%)$ & Neutral (\%) & Agree $(\%)$ \\
\hline Goal to eat healthy & $3 \cdot 70$ & $3.41,3.98$ & $15 \cdot 94$ & 11.59 & 72.46 \\
\hline Unhealthy eating is part of the football culture & $3 \cdot 13$ & $2.90,3.36$ & 31.03 & $22 \cdot 41$ & $46 \cdot 55$ \\
\hline Often buying the same products & 2.95 & $2 \cdot 60,3 \cdot 31$ & 35.59 & $27 \cdot 12$ & $37 \cdot 29$ \\
\hline Often buying products without thinking & 2.42 & $2.08,2.77$ & $59 \cdot 32$ & $18 \cdot 64$ & $22 \cdot 03$ \\
\hline Importance of stimulating healthy eating by canteen & $4 \cdot 21$ & $3.90,4.52$ & $12 \cdot 07$ & $8 \cdot 62$ & $79 \cdot 31$ \\
\hline Current supply is healthy enough & $3 \cdot 75$ & $3.48,4.03$ & 13.56 & $25 \cdot 42$ & 31.02 \\
\hline
\end{tabular}




\section{Intervention level}

As mentioned in the 'Adherence' section, many characteristics of the products used in the intervention could, according to the interviewees, be altered to increase adherence, which, in turn, could increase sales and vice versa: shelf-life (should be medium to long), familiarity of products (should be high), flavour (products should have a nice taste) and the quantity for money (more food for less money). The effort (time and physical) in maintaining the nudge was mentioned as a characteristic of nudges that could increase the effect of the intervention. The fit between nudges and the organisational possibilities and constraints was deemed important.

Although interviewees were generally positive about the intervention, they all expressed the opinion that nudges alone are not enough to make a difference in the diets of visitors. Some of the interviewees were willing to implement more rigid measures, for example, by not selling fried foods to children and by radically reducing the number of unhealthy items sold. Others were more positive about expanding the product range with healthy items and by slowly reducing the product range of unhealthy items. For them, the way to a healthy canteen is a slow, multi-year process.

Interviewees of both canteens indicated to continue with the sale of most products after the study, except for the yogurt and the savoury snack in both canteens and the grilled sandwich in canteen B. They also indicated to continue using the nudges connected to these products, except for the prompted choice nudge. Although interviewees mentioned the benefit of increasing sales of these healthy products by continuing the nudges, they also mentioned that this choice was mostly based on the desire not to change the (by now well established) position of the products.

\section{Organisational level}

Many visitors agreed with the notion that it is important that the football canteen stimulates healthy eating. Most also agreed that the current supply of healthy products is high enough.

Interviewees of both canteens agreed that it is important for football canteens to promote healthy eating. However, they also placed importance on providing visitors with the choice between healthy and unhealthy products. They felt more responsible for children than for adults, although they also considered that the ultimate responsibility for a healthy diet does not rest upon the football canteen but with parents/guardians:

I do think that, when they come bere, we should offer an alternative for all the unbealthy products we sell. I do feel responsible for a bealthy product range, and also that we show these products, but I don't feel responsible for obligating children or parents to

buy such things. - Board member, male, canteen B

The importance that is placed on the promotion of healthy eating is reflected in board members of both canteens stating that the sale of healthy products can come with the drawback of lower revenues. In canteen $\mathrm{B}$, healthy products are often sold against cost price. However, losses should not be too big, since the profits from the canteens constitute a significant part of the budget of the football clubs. Therefore, the interviewees of canteen B also mentioned that, despite their being unhealthy, the best-sold products will not be removed from the product range.

\section{Discussion}

The current study explored the potential of nudge interventions to promote healthy eating in sports canteens. Sales records showed an increase in the consumption of nudged products. Willingness and acceptability to use nudges were high for both receivers and choice architects, and many people were exposed to the intervention. However, adherence to the intervention turned out to be quite difficult. Moreover, in light of the overwhelming amount of unhealthy products that were sold in the canteens in comparison with the small proportion of healthy alternatives, doubts were raised about the magnitude of the possible impact of the use of only nudges on eating behaviour. These results paint a moderately positive picture of the use of nudges in guiding consumers towards better food choices.

The current study demonstrates the difference between the effects of nudges achieved in earlier studies in controlled environments $v$. the real-life circumstances in the current study. The low adherence rates to the intervention are especially striking in this regard, since the intervention can be argued to be straightforward and its initial implementation appeared to be relatively easy. However, canteen personnel found it demanding to have all products in stock and to adequately follow the nudge protocol.

Only few studies explored the effects of repeated nudge exposure. It has been suggested that effects tend to fade over time, with $35-55 \%$ of changes persisting after the intervention $^{(32)}$. However, other studies suggest that duration of nudge exposure does not moderate the effect of nudges on eating behaviour ${ }^{(16)}$. The reported sales figures in our study do suggest a pattern of increase right after implementation, followed by a decrease and again by a slight increase. The inconclusive results regarding longterm effects of nudges suggest more long-term follow-up research on nudges is needed.

More importantly, the results also prompt questions about the ability of nudge interventions to significantly impact public health. Although positive, the effect of the 
nudges on sales was small. When the extra number of sold products is compared with the number of visitors, it can be deduced that the intervention is not likely to have induced a substantial health gain. Moreover, although a significant proportion of the products was nudged, sales records were still dominated by unhealthy products such as alcoholic beverages, sugary drinks and deep fried foods. It thus seems that the nudges could not overcome the many factors that determine food choice such as the easy accessibility and high availability of unhealthy foods and existing food preferences and habits ${ }^{(33)}$. Because products used in the intervention were close alternatives to existing products, these results imply that more concurrent strategies are needed to significantly impact eating behaviour. For example, in a systematic review on point-of-sale strategies to increase healthier eating by Liberato et al. ${ }^{(34)}$, monetary incentives are put forward as an effective point-of-sale strategy, while evidence on point-of-sale nudges was found inconclusive.

The ethical implications of nudging are a topic of scholarly discussion ${ }^{(35,36)}$. Interestingly, both the public and the organisations of the football clubs were positive about the use of nudges to promote healthy eating. This finding is supported by other studies that focussed on the acceptability of nudges by those that are being nudged. For example, Reisch \& Sunstein collected acceptability rates of five countries on a range of different nudges and found that on average, $63 \%$ approved of the nudges, although acceptability rates did depend on type of nudge and country ${ }^{(37)}$. One could argue that behavioural influencing techniques accepted by those that are being influenced are inherently non-manipulative. Although the small minority that considered the use of nudges unacceptable in the current study should by no means be ignored, the current study does suggest that the acceptability of nudges does not pose a problem for the implementation of nudge interventions to promote healthy eating in sports canteens.

The habitualness of unhealthy eating behaviour and the unhealthy eating culture surfaced as having acted as a barrier for the influence of nudges on eating behaviour during interviews with board members and canteen personnel, but not from the questionnaires with visitors. This discrepancy may be caused by an inability to identify one's own behaviour as automatic ${ }^{(3)}$, since sales and interviews clearly show the canteens to be environments in which unhealthy eating dominates (despite the large number of visitors reporting a strong healthy eating goal). Because of these persistent unhealthy eating habits, board members and canteen personnel were sceptical about the ability of nudges to change behaviour, especially with adolescents and adults. However, eating behaviour of children was still seen as mouldable, a statement that needs further research ${ }^{(32)}$. This view coincides with the responsibility voiced by the interviewees to promote healthy eating behaviour among children.

\section{Strengths and limitations}

Although only two cases were examined in the current study, they enabled a multi-method in-depth analysis of many aspects of the outcome and process evaluation. Such analyses are uncommon in the outcome-oriented literature on nudges, which mostly consists of short-term experimental studies. This allowed the identification of elements that deserve consideration when designing and implementing a nudge intervention to promote healthy eating. Moreover, the timeline of the intervention enabled exploring the effect of nudges over a longer period, generating hypotheses for important unanswered questions.

The current study also has limitations. The effects of the nudges on sales are likely underestimated, since, during the interviews, it became clear that often incorrect buttons are pressed at the register when prices for products are similar (e.g., the regular instead of the zero-sugar version). Also, both canteens that participated in the study expressed a high motivation for adding and promoting healthy products and underlined that this is uncommon among football clubs. This may have inflated acceptability rates. Although deviations from protocol were corrected during visits at which adherence was measured in canteen A, betweenvisit adherence was still suboptimal (which follows the low adherence rate at most visits). Therefore, the added focus on the validity of results related to the outcome in canteen A was lost.

\section{Future research}

The current study highlights the importance of a further exploration of the potential and limits of nudges to impact public health. How sustainable are the effects of nudging on eating behaviour? What are the prerequisites for, and processes that underlie, long-term effects of nudges? Moreover, to substantially impact health, additional evaluation studies are needed to further assess the potential of nudges, with or without other measures that act in concordance with nudges.

\section{Conclusions}

It may have become clear that the reputation of nudges as an easy, cheap and effective means to use in interventions aimed at increasing healthy eating needs reconsideration. An adequate translation from theory to practice needs to take into account the many factors related to the target group and the context, all of which could affect the intervention's outcomes. Moreover, the impact of localised nudge interventions on health seems to be minimal considering the complex contexts in which food choices are made. Therefore, nudge research should make room for questions that answer which, where, how, for whom and how long nudges are beneficial in the battle against unhealthy eating. 


\section{Acknowledgements}

Acknowledgements: We would like to thank Dr Marieke Adriaanse, Prof. Denise de Ridder and Laurens van Gestel from Utrecht University and Prof. Marcel Verweij and Dr Eva Groen-Reijman from Wageningen University for their insightful remarks during the research. Financial support: The current research was funded by a grant from ZonMW, Netherlands Organisation for Health Research and Development (project no. 91215012). ZonMW did not have any role in the design, collection, analysis and interpretation of data and in the writing of the manuscript. Conflict of interest: There are no conflicts of interest. Authorship: M.v.R. designed the study, collected the data and drafted the manuscript. E.d.V. designed the study and reviewed and revised the manuscript. Both authors read and approved the final manuscript. Ethics of human subject participation: The current study was conducted according to the guidelines laid down in the Declaration of Helsinki and all procedures involving research study participants were approved by the Social Sciences Ethics Committee of Wageningen University. Written informed consent was obtained from all interviewees. For all questionnaires used in the study consent was implied, meaning that respondents were informed at the top of the questionnaire about the goal of the study and their rights. Moreover, people had to actively grab the questionnaires without the researcher asking for participation. Trial registration: The Netherlands Trial Register, no. 6718, date of registration: 17 August 2017, https://www.trialregister.nl/trial/6530.

\section{Supplementary material}

For supplementary material accompanying this paper visit https://doi.org/10.1017/S1368980020002013

\section{References}

1. Webb TL \& Sheeran P (2006) Does changing behavioral intentions engender behavior change? A meta-analysis of the experimental evidence. Psychol Bull 132, 249-268.

2. Cohen J (1992) A power primer. Psychol Bull 112, 155-159.

3. Bargh JA (2002) Losing consciousness: automatic influences on consumer judgment, behavior, and motivation. J Consum Res 29, 280-285.

4. Cohen DA \& Babey SH (2012) Contextual influences on eating behaviours: heuristic processing and dietary choices. Obes Rev 13, 766-779.

5. Kahneman D (2011) Thinking, Fast and Slow, 1st ed. New York: Farrar, Straus and Giroux Inc.

6. Strack F \& Deutsch R (2004) Reflective and impulsive determinants of social behavior. Pers Soc Psychol Rev 8, 220-247.

7. Kahneman D \& Tversky A (1973) On the psychology of prediction. Psychol Rev 80, 237-251.

8. Thaler RH \& Sunstein CR (2008) Nudge: Improving Decisions About Health, Wealth and Happiness. 1st ed. New Haven, CT: Yale University Press.
9. Tversky A \& Kahneman D (1974) Judgment under uncertainty: heuristics and biases. Science 185, 1124-1131.

10. Maas J, de Ridder DT, de Vet E et al. (2012) Do distant foods decrease intake? The effect of food accessibility on consumption. Psychol Health 27, Suppl. 2, 59-73.

11. Marteau TM, Hollands GJ \& Fletcher PC (2012) Changing human behavior to prevent disease: the importance of targeting automatic processes. Science 337, 1492-1495.

12. Arno A \& Thomas S (2016) The efficacy of nudge theory strategies in influencing adult dietary behaviour: a systematic review and meta-analysis. BMC Public Health 16, 676.

13. Roy R, Kelly B, Rangan A et al. (2015) Food environment interventions to improve the dietary behavior of young adults in tertiary education settings: a systematic literature review. J Acad Nutr Diet 115, 1647-1681.

14. Szaszi B, Palinkas A, Palfi B et al. (2018) A systematic scoping review of the choice architecture movement: toward understanding when and why nudges work.J Behav Decis Mak 31, 355-366.

15. Veccio R \& Cavallo C (2019) Increasing healthy food choices through nudges: a systematic review. Food Qual Prefer 78, 103714.

16. Cadario R \& Chandon P (2020) Which healthy eating nudges work best? A meta-analysis of field experiments. Market Sci 39, 459-665.

17. Glasgow RE, Lichtenstein E \& Marcus AC (2003) Why don't we see more translation of health promotion research to practice? Rethinking the efficacy-to-effectiveness transition. Am J Public Health 93, 1261-1267.

18. van Kalmthout J (2012) Healthy sports canteen? Exploration among sports directors commissioned by the Ministry of Health, Welfare and Sport; available at https://www. kennisbanksportenbewegen.nl/?file $=2024 \& \mathrm{~m}=1422883019 \&$ action=file.download (accessed May 2019).

19. Allan J, Querstret D, Banas K et al. (2017) Environmental interventions for altering eating behaviours of employees in the workplace: a systematic review. Obes Rev 18, 214-226.

20. Bucher T, Collins C, Rollo ME et al. (2016) Nudging consumers towards healthier choices: a systematic review of positional influences on food choice. Br J Nutr 115, 2252-2263.

21. Cruwys T, Bevelander KE \& Hermans RC (2015) Social modeling of eating: a review of when and why social influence affects food intake and choice. Appetite 86, 3-18.

22. Engbers LH, van Poppel MN, Paw MJCA et al. (2005) Worksite health promotion programs with environmental changes: a systematic review. Am J Prev Med 29, 61-70.

23. Escaron AL, Meinen AM, Nitzke SA et al. (2013) Supermarket and grocery store-based interventions to promote healthful food choices and eating practices: a systematic review. Prev Chronic Dis 10, 120156.

24. Gittelsohn J, Rowan M \& Gadhoke P (2012) Interventions in small food stores to change the food environment, improve diet, and reduce risk of chronic disease. Prev Chronic Dis 9, E59.

25. Glanz K \& Yaroch AL (2004) Strategies for increasing fruit and vegetable intake in grocery stores and communities: policy, pricing, and environmental change. Prev Med 39, $75-80$.

26. Harnack LJ \& French SA (2008) Effect of point-ofpurchase calorie labeling on restaurant and cafeteria food choices: a review of the literature. Int J Behav Nutr Phys Act 5, 51.

27. Hollands GJ, Shemilt I, Marteau TM et al. (2013) Altering micro-environments to change population health behaviour: towards an evidence base for choice architecture interventions. BMC Public Health 13, 1218. 
28. Libotte E, Siegrist M \& Bucher T (2014) The influence of plate size on meal composition: literature review and experiment. Appetite 82, 91-96.

29. Skov LR, Lourenco S, Hansen GL et al. (2013) Choice architecture as a means to change eating behaviour in self-service settings: a systematic review. Obes Rev 14, 187-196.

30. Wilson AL, Buckley E, Buckley JD et al. (2016) Nudging healthier food and beverage choices through salience and priming: evidence from a systematic review. Food Qual Prefer 51, 47-64.

31. Hawe P, Shiell A \& Riley T (2004) Complex interventions: how "out of control" can a randomised controlled trial be? BMJ 328, 1561-1563.

32. Brandon A, Ferraro PJ, List JA et al. (2017). Do the effects of social nudges persist? Theory and evidence from 38 natural field experiments. NBER Working Paper Series No. 23277. Cambridge, MA: National Bureau of Economic Research.

33. Glanz K, Basil M, Maibach E et al. (1998) Why Americans eat what they do: taste, nutrition, cost, convenience, and weight control concerns as influences on food consumption. $J \mathrm{Am}$ Diet Assoc 98, 1118-1126.

34. Liberato SC, Bailie R \& Brimblecombe J (2014) Nutrition interventions at point-of-sale to encourage healthier food purchasing: a systematic review. BMC Public Health 14, 919.

35. Wilkinson TM (2013) Nudging and manipulation. Political Stud 61, 341-355.

36. Goodwin T (2012) Why we should reject 'nudge'. Politics $\mathbf{3 2}$, 85-92.

37. Reisch LA \& Sunstein CR (2016) Do Europeans like nudges? Judgm Decis Mak 11, 310-325. 